\title{
INTERNATIONALIZATION AND THE ASSESSMENT OF RESEARCH QUALITY IN EDUCATION*
}

Over the period 2006-2008, I had the privilege of being a panel member of an assessment panel with the UK's Research Assessment Exercise 2008 (RAE 2008). When I was asked to join the panel I was not sure about the role I was expected to perform. Nor was I entirely convinced that, as a scholar who regarded himself as 'critical', I would be entirely comfortable performing a state-mandated task. I knew I was expected to assess the quality of educational research in Britain, but I was less clear as to how my assessment would feature in the calculations by which individual and institutional careers might be affected. I was told that I was to represent an 'international' voice on the panel, helping it assess how British research 'stacked up' against some presumed international standard. This was indeed a daunting task, not least because the criteria by which this standard was to be judged was left entirely unspecified. The assumption was that I would somehow know instinctively what this was, on the basis of my own work as a researcher and my familiarity with international research networks.

After much reflection, I accepted the challenges associated with this role, while remaining mindful of an acute observation made by the late Edward Said in his 1993 Reith lectures, later published as Representations of the Intellectual. Said (1994) argued that critical scholars working for the state occupied an ambiguous position, for they could not afford to be too much 'out of step' with the established rules of governance, while as critics they could not afford not to be. A way out of this dilemma, he suggested, was for critical scholars to work pragmatically, to speak the language of the state but keep that language unstable enough so that their ability to be critical was never compromised. This was good advice, which I sought to follow at all times, always interested in theorizing the relationship between state patronage and the production of research, within a framework that recognizes the needs of the state and universities to assess research performance for a wide variety of purposes, and to use the discourse of international significance to position themselves within an increasingly globalized market in higher education. However, as a critical scholar, I continued to be sceptical of the politics surrounding these developments, insisting on the need to imagine more radical possibilities associated with the idea of internationalization of educational research.

As is widely known, the idea of 'international' is used in research assessment schemes not only in the United Kingdom but also in Hong Kong and New Zealand where similar schemes exist and other places like Australia where it is being developed. Indeed, in describing its criteria for judging the relative merits of submitted research, RAE 2008 invoked the idea of 'international' in no less than 
three of the four different grades it awarded, and in the fourth it was implied, where 'national' was read as 'non-international'. It was explicit in maintaining that the quality of research was to be judged in terms of originality, significance and rigor, but also in suggesting that these criteria of quality might themselves be defined, interpreted and judged in international terms. In this way, 'international' served as a kind of meta-criteria. This construction is expressed widely in such notions as 'internationally refereed', 'internationally benchmarked', 'internationally recognized' and 'world class' used not only by RAE2008 but also by funding bodies and universities around the world in articulating their aims and objectives. So much as so that this discourse might itself be said to have become globalized.

Yet when we look more closely at this discourse, it is abundantly clear that the term 'international' is often taken to have a self-evident meaning. Seldom is it analysed in any systematic fashion, even by the critics of research assessment schemes. It thus serves as a symbolic marker - as an honorific title for research that is considered meritorious in terms of originality, significance and rigor, as judged by peers, panels and commentators alike. Over the years, a large literature has emerged in relation to the politics of research assessment schemes, especially about of the ways it enables states and organizations to establish frameworks for distributing research funds, for holding researchers accountable and for steering them towards certain priorities. Some of this literature also seeks to explain the origins and the popularity of research assessment schemes in terms of the new management practices in higher education, the dynamics of neo-liberal state policies and the requirement of the globalizing knowledge economy. The impact of these schemes on the professional practices of research, the formation of research communities and the organizational changes and leadership has been investigated; as is the manner in which such schemes are utilized to strengthen policy and practice in education. It is often assumed that such mechanisms represent a culture of performativity (Lyotard, 1984), or an 'audit culture' (Strathern, 2000)

At the conceptual level, numerous educational scholars have sought to reexamine the concepts of originality, significance and rigor in educational research, seeking to provide greater depth to our understanding of these criteria, and how they might be aligned to the diversity of methodological traditions. They have also commented on the requirements of greater impact, affectivity and relevance to educational practice. In Australia, Lyn Yates (2006), for example, has written eloquently about how the notion of significance in educational research might be interpreted, and to what extent it is possible to measure the impact of educational research. In Britain, John Furlong (Furlong \& Oancea, 2006) has led a team of researchers and users of educational research to develop a framework for assessing quality and practice-based research in education. In Canada, Ben Levin (2005) has put forward a powerful argument about how research in education can contribute to the production and assessment of education policy. And in New Zealand, John Codd (2006) has described the origins and the broader organizational politics of research assessment systems. In a more policy and practical context, I remain full of admiration for the members of the sub-panel on Education for RAE2008, under the leadership of Margaret Brown, who struggled to understand in operational 
terms the criteria of originality, significance and rigor so that these were inclusive of the diverse methodological traditions of educational research, and also of the needs of most stakeholders in Britain's educational community.

Now, for all this outstanding work, there is remarkably little that has been published on the idea of internationalization as a criterion for assessing research quality. This is indeed surprising given the theoretical and policy importance attached to it. A major exception to this is a highly perceptive and insightful analysis presented by David Bridges (2007). In his paper, Bridges has sought to examine the relationship between the discourse of international on the hand and the discourse of research quality on the other. He has identified a number of problems with the application of the concept of 'international' to make judgments of research quality. He has noted that each of the key criteria of originality, significance and rigor of research raises questions of not only 'of what' but also 'for whom'. And the question of 'for whom' inevitably raises the issue of the geographical scope of the reach of educational research, both through its international dissemination and its impact. RAE2008 specifically suggested that 'spatial' considerations of geography should not enter into an assessment of quality, but it has always been hard for me to imagine how the idea of 'international' could be conceptually untied from these considerations, for 'international' is inextricably a spatial concept.

In making and supporting judgments of quality in educational research, the idea of 'international' could be interpreted in a number of ways. First, it might be suggested that to meet some international criteria of rigor, originality and significance is to invoke certain universal standards by which research quality is judged. This would suggest that no matter who, where and how a particular piece of research is done, the same standards are applicable, and that those who have been initiated into these standards would recognize it without hesitation. Here, the assessment of research quality is not tied to any particular socio-spatial context, but is based instead on universally recognized criteria appropriate to particular disciplines, determined either transcendentally or made through some historical generalization. One suspects that it is this idea of 'international' that RAE2008 had in mind; and that, as a result, it envisaged that the role of the international panel members was to authenticate the application of these universal criteria to particular pieces of research.

Now while the appeal of this universalistic understanding of international excellence is understandable, based as it is within positivist and rationalist epistemological traditions, articulated against the dominant western conception of enlightenment and modernity, it has in recent decades become increasingly difficult to sustain it. Some fifty years ago few would have challenged its plausibility. But in light of recent post-structural, post-colonial and feminist critiques of the notion of universal reason, it is no longer possible to accept its assertions of absolutism and certainty. Sociologists of knowledge have shown that any claim to such universality is located in a history, and that it serves only to benefit particular political interests. Following Wittgenstein (1973), it is widely argued that all language games, and by implication, including those associated with claims to rigor, originality and significance, are located within particular forms of 
life. And even more strongly, Foucault's analysis (1980) of the relationship between power and knowledge suggests that all epistemic claims are subject to genealogical analyses. And if this is so then a universalism inherent in many claims about research quality is at least contestable.

A second way of thinking about 'international' in the assessment of research quality is to tie it to bibliometric considerations. In this way, 'international' might signal the fact that a given piece of research is published in an internationally renowned journal, following a rigorous process of refereeing. This might suggest that the journal is read and admired widely, perhaps even internationally, and serves as something of a bearer for the standards of quality. Plausible though this line of thinking might be, on both pragmatic and historical grounds, I find this reasoning to be circular: for quality is judged in terms of the journal and the journal in turn is considered meritorious because of its quality. So while the high regard in which the journal is held around the world could arguably be regarded as a necessary condition for judging quality it can hardly be assumed to be sufficient. Given the multiplicity of theoretical, methodological and political positions, the claim of quality of a journal is almost invariably contested by some, especially in the humanities, social sciences and professional disciplines such as Education.

There are a number of other reasons why the bibliometric approach to the assessment of research quality is inadequate. Some of these relate to its cultural and language bias towards research published in English, which potentially marginalizes both the content and approaches to knowledge not located within the English-speaking world. Goodall (2006) has argued that the bibliometric approach favors natural sciences over the social sciences and humanities. It moreover favours research that pursues particular methodological approaches based on a scientific paradigm expressed in terms of the norms of replicability of experiments and the generalizability of results. It sidelines interpretative and critical research based on creative insights into evolving phenomenon such as those associated with globalization. It also marginalizes narrative and oral traditions of research, valued and cherished in many indigenous communities (Tuhiwai Smith, 1999).

The bibliometric approach of such research assessment technologies as RAE2008 is often associated with the practices of citation. But the use of citations in judging quality and research impact is not without its problems. Authors often self-cite and receive citations for both 'bad' and 'good' works. So citations practices are at best only indicative of quality - and certainly not its key measure. A more serious problem with the bibliometric approach is acutely revealed in any examination of the political economy of publishing, relating to such issues as how journals are now produced and marketed, the ways in which commercial interests often steer the publication of particular kinds of research and not others, and the manner in which commercially-driven publishing reproduces the current asymmetrical circuits of knowledge production, circulation and utilization. As Michael Peters (2007) has argued, the relationship between publishing houses and academic researchers is a symbiotic one, which needs to be elaborated, if we are to appreciate the political economy of research and its assessment. 
A third perspective on the concept of 'international' might involve accepting the need to view research quality in spatial terms, pertaining to the geographical reach of a particular set of ideas and their take-up in educational policy and practice around the world. This approach might extend the bibliometric perspective by looking at the extent to which a particular research is applicable across places beyond that in which it is produced - that is, beyond the reach of the normal circuits of bibliometric circulation among, for example, the non-English-speaking audiences. The quality of research might furthermore be judged in terms of its preparedness to engage with a wider range of topics embedded in and dealing with various 'other' cultural traditions, often in ways that are comparative. The originality might consist in its applicability across a range of cultural and educational traditions. Issues of scale might be relevant here, in terms of the research's symbolic and material impact, and of the extent to which it is referred to and utilized and generally held in esteem not only within the West but also in other parts of the world.

However, it is possible for such an approach to the internationalization of research to still remain tied to the existing relations of power. Appadurai (2000: 16) uses the term 'weak internationalization' to refer to those practices of research which while accepting the need to build international and democratic community of researchers nonetheless assume the existing 'research ethic as given and unquestionable'. He contrast this with a 'stronger notion of internationalization', which is more clearly characterized by its attitude of openness. It implies supporting creative ideas about education and educational research that are not constrained by the narrow requirements of methodological rectitude but encourage instead a spirit of exploration and respect for traditions of thinking that have been marginalized by the legacy of the positivist orientation. Here research is judged not in terms of the extent to which methodological rules and protocols are followed but the ways in which it articulates new ideas and innovation and intercultural comparison, especially about those matters that involve cross-cultural variations. This approach invites - perhaps even demands - speculation, criticality and reflexivity. It encourages 'playing' with concepts in a spirit of experimentation involving conjectures and refutations, as Karl Popper (1978) so eloquently put it many years ago. It encourages democratic debate that is not confined to professional researchers within the familiar geographical spaces, but spans many diverse communities.

Never before has this attitude of openness to educational research more important than in our contemporary social context characterized by rapid economic, political and cultural change; and by global interconnectivity and interdependence, forged at an unprecedented speed and intensity. This context has rendered many of our traditional concepts and categories unstable and deeply problematic. These now hang uneasily on the hinges of certainty. Even such takenfor-granted concepts in education as 'the society', 'the public' and 'the school' do not any longer admit uniform and universal definitions. This is so because the social field within which education now takes places is increasingly transformed by the complex processes associated with the global mobility of ideas and people, and 
by the transnational circuits of communication and power. This transformation no longer permits us to sideline or simply ignore interpretations that lie outside our immediate field of vision, by other communities that might interpret global realities differently. So, for example, the idea of 'the public' that education is meant to serve can no longer be defined solely in national terms, but must attend to the issues of global interconnectivity and networks and to the scope of our responsibility.

The rapid and intense social changes affected by globalization and the advances in the information and communication technologies raise new questions in both our personal and professional lives at almost every turn of world events. September 11, for example, raised new questions about the politics of terror, how best to represent and respond to it. The events in the summer of 2005 and 2006 in the United Kingdom demanded that we re-think about how our communities are globally constituted, and how purely national responses to the issues faced by our students may not be sufficient. Throughout the world, we are witnessing major demographic transformations, economic upheaval, political shifts, social changes resulting from the ways people use media and technology and new cultural formations, especially among the young. Local politics are stretched in new ways, especially when the diaspora is able to remain in touch with and exercise power in the communities they left behind.

If localities around the world are now becoming 'transnationalized' then the implications for educational research are also profound and potentially involve new ways of assessing its quality. How do we, for example, research spaces that do not have any clear boundaries and where social relations potentially span vast distances? How do we take into account the distribution and dynamics of power whose contours potentially involve the entire globe? How do we provide accounts of social meaning when these are not linked to any specific community? How do we study social inequalities when its causes do not necessarily reside within the community that is the object of our research? In other words, how do we address the conceptual difficulties that inevitably arise in modes of social research when the very constitution of 'the social' cannot be easily defined?

Educational research has traditionally involved the collection and analysis of information about how teachers and students relate to each other - how they make social meaning - within some specified locality or organization. This implies that research almost inevitably occurs within an assumed space, be it a social organization like a school or a community marked by deep, familiar and cooperative ties between its members and defined by its geographical borders. While educational research can, of course, have many purposes - to provide an account of social identities, to understand how students make meaning of their lives, to understand the changing nature of teachers' work, explain social, economic and political relations expressed in education policy, to reveal patterns of inequality and power, to determine deep structural barriers to the realization of objectives of reform and so on - it always takes place within a space. We cannot therefore ignore issues of how, in the era of globalization, space is constituted and how its boundaries are drawn. 
Of course, space is never constituted in a uniform and consistent manner. Not all spaces are transnationalized in the same way or, indeed, to the same extent. Some spaces, like global cities (Sassen 1995) such as Chicago and London, have become transnationalized to a greater extent than isolated rural communities in Africa, for example. In this sense, transnationalization may be viewed as an on-going dynamic social process affected by changing forms of connectivity between the global and the local, between a community's interior and its exterior. At a conceptual level, however, the notion of a transnational space would seem to undermine any meaningful distinction between the inside of a space and its outside, long regarded as central to social and educational research. If such traditional naturalistic distinctions as the inside and outside of a community or an organization cannot be easily maintained, then many new questions emerge for educational research that takes seriously the idea of 'international'.

In recent years, numerous ethnographers have pointed out, for example, that, in the emerging global context, both the ideas of 'ethno' and 'graphic' have become problematic. The relationship between ethnographers and the people they studied was already complex, but in transnational spaces, new questions arise around such key terms as 'othering' and 'authorial' control, leading to what Wittel (2000: 1) calls, a 'crisis in objectification'. With respect to the idea of 'ethno', a culture can no longer be treated as a coherent entity, unique from and unaffected by its engagement with other cultures. Through enhanced mobility of capital, people and ideas, cultural contact has become a norm, leading Clifford (1997) to suggest that human location is now constituted by displacement as much as by status. With the deterritorialization, pluralization and hybridization of cultures, the notion of 'the field' as a geographically defined research area has also become more complex. As Marcus and Fischer (1986) point out, the transnational, political, economic and cultural forces that now shape localities have undermined the traditional notion of 'the field'. Gupta and Ferguson (1997) therefore suggest the need to redefine the notion of 'the field', by 'decentring' it in ways that deny any clear cut distinction between 'the here' and 'the elsewhere'.

If people and objects are increasingly mobile then, Gupta and Ferguson (1997) argue, ethnography has to engage these movements and, with them, the ways in which localities are a product of the circulations of meanings and identities in timespace. Educational research is becoming embedded with the world systems, shifting its focus from single sites and local situations to become multi-sited and multi-local, responsive to networked realities. Castells (2000) has drawn our attention to the ways in which our communities are becoming globally networked. A 'network society', for Castells, is an open structure, able to expand without limits and in ways that are dynamic. It consists of a set of nodes and connections across the nodes, characterized by flows and movement. The Internet is a good example of how its ubiquitous uses are re-shaping our everyday practices, affected, as they are, by the ways in which information flows across various nodes of networks, in spaces that are highly mediated and interactive. These nodes are often transnational, and deeply connect us to social networks that do not necessarily reside within a specific territory. Research then is increasingly characterized by 
greater levels of displacement, dynamism, contingency, plurality and complexity. This challenges some of the most taken-for-granted categories in educational research. It demands new theoretical and methodological resources.

Most importantly, it requires a new research ethic, as Appadurai (2001) has insisted. If educational research is to adequately address these complexities surrounding the new global realities, and the challenges they pose, then such an ethic needs to acknowledge how societies are imbricated with unequal power relations, which reflect both contemporary geo-politics and past political struggles. Recognition of the researcher's positionality within Western universities and their relationships to these geographies of power could be a beginning for challenging the silent valorization of Western epistemologies in research of all kinds, including education policy research. Such a challenge is central to what Appadurai (2001: 15) calls the 'deparochialization' of research, in the light of enhanced global flows of students and academics as part of the mobilities and networks of globalization. He argues for the need to deconstruct in both an anthropological and pragmatic sense, the 'taken for granted' assumptions of the contemporary systems of research. In the context of increased flows of capital, people, ideas, images and technologies and disjunctions and related asymmetries of power, he suggests a number of ways in which the dominant research ethic might be challenged, including a reconnection with earlier pre research paradigm thinking premised on a strong moral position; the promotion of the style of argumentation of public intellectuals; and paying greater attention to research linked to policy making and state functions in a range of nations, particularly those in the developing world.

Appadurai maintains that 'epistemological diffidence' is necessary for deparochializing research. This must involves challenging the assumptions pf modernization theories that accepted without question that theory and research were metropolitan, modern and western, while the rest of the world was simply a research site to test and confirm such theory. Here relations of researcher and researched paralleled relations of coloniser and colonised, even within decolonising and postcolonial politics and aspirations. Linda Tuhiwai Smith (1999) similarly calls for Decolonizing Methodologies in her study of the relationship between research and Indigenous peoples and knowledge in New Zealand, where she suggests that the term 'research' is 'inextricably linked to European imperialism and colonialism'. Relations of power and politics in both macro and individual relations senses distort even the most arcane theories to some extent' (Lingard 2006: 34).

In rejecting an epistemological innocence characteristic of the dominant forms of education research, both Appadurai and Smith call for an 'epistemological openness'. Such a project, according to Appadurai, needs to be aligned with 'grassroots globalization' or 'globalization from below'. We need to ask: whose globalization? and in doing so, issue a challenge to globalization from above as driven by leading international organizations and the global cultural industries (Klein, 2001). Appadurai emphasizes the need for research to examine its own rhetoric and practices of 'systematicity, prior citational contexts, and specialized modes of inquiry', replicability, along with 'an imagined world of specialized 
professional readers and researchers’ (Appadurai, 2001: 12) which taken together work to inhibit the deparochialization of research, its theories and methodologies. Prior citational contexts and an imagined world of specialized readers ensure the reproduction of more 'parochial', western dominated theories.

What this analysis demonstrates then is that the notion of internationalization assumed by RAE2008's assessment technology was based on existing geographies of knowledge and geometries of power (Epstein, 2008). RAE2008 used the idea of 'international' to simply reproduce and privilege the existing practices of research, and in doing so it failed to open up a discussion how the current realities of globalization, and how these require a new research ethic of openness to a greater diversity of theoretical and methodological traditions that are not tied to the western academy. However, on a personal note, my participation on a RAE2008 panel gave me an opportunity to reflect on the ways in which educational research is funded, conducted and assessed for thinking, and how the state plays a crucial role in promoting certain kinds of research and not others, in prioritizing certain research questions, and in privileging certain methodological approaches. It also confirmed for me Appadurai's insight (2001) that 'strong internationalization' in unlikely to come from the processes of 'globalization from above' but only through 'grassroots globalization', which involves the creation of communities and conventions of research in which membership does not require unquestioned prior adherence to existing norms, and that the term 'international' need not inevitably be 'the property of state-capital' nexus.

\section{NOTES}

* This paper is a revised version of the Routledge Lecture delivered at the annual conference of the British Educational Research Association in Warwick England, September 2006

\section{REFERENCES}

Appadurai, A. (Ed.). (2001). Globalization. Durham, NC: Duke University Press.

Castells, M. (1996). The rise of the network society. Oxford: Blackwell.

Clifford, J. (1997). Routes: Travel and translation in the late twentieth century. Cambridge: Harvard University Press.

Codd, J. (2006). Assessing research quality: The origins and outcomes of New Zealand's performancebased research fund. In J. Blackmore, J. Wright, \& V. Harwood (Eds.), Counterpoints on the quality and impact of educational research (pp. 43-56). Melbourne: Australian Association for Research in Education.

Epstein, D., Boden, R., Deem, R., Rizvi, F., \& Wright, S. (Eds.). Geographies of knowledge, geometries of power: Framing the future of higher education. London: Routledge.

Furlong, J., \& Oancea, A. (2006). Assessing quality in applied and practice-based research in education: A framework for discussion. In J. Blackmore, J. Wright, \& V. Harwood (Eds.), Counterpoints on the quality and impact of educational research (pp. 89-104). Melbourne: Australian Association for Research in Education.

Foucault, M. (1980). Power/Knowledge: Selected interviews and other writings, 1972-1977. London: Harvester Press.

Goodall, A. (2006). The place of citations in today’s academy. International Higher Education, 43. 
Gupta, A., \& Ferguson, J. (1997). Culture, power and place: Explorations in critical anthropology. Durham, NC: Duke University Press.

Levin, B. (2005). Governing education. Toronto, ON: University of Toronto Press.

Lyotard, J.-F. (1984). The postmodern condition. Minneapolis, MN: University of Minnesota Press.

Marcus, G., \& Fischer, M. (1986). Anthropology as cultural critique: An experimental moment in the human sciences. Chicago: University of Chicago Press.

Massey, D. (2005). For space. London: Sage.

Peters, M. (2007). Knowledge economy, development and the future of higher education. Rotterdam: Sense Publishers.

Popper, K. (1978). Conjectures and refutations: The growth of scientific knowledge. London: Routledge.

Said, E. (1993). Representations of the intellectual. London: Vintage.

Sassen, S. (1995). The global city: New York, London and Tokyo. Princeton, NJ: Princeton University Press.

Tuhiwai Smith, L. (1999). Decolonizing methodologies: Research and indigenous peoples. London: Zed Books.

Strathern, M. (2000). Audit cultures. London: Routledge.

Wittel, A. (2000). Ethnography of the move: From field to net to internet. Qualitative Social Research, 1(1), online journal. Retrieved January 2006, from http://qualitative-research.net/fqs

Wittgenstein, L. (1973). Philosophical investigations. Cambridge: Blackwell.

Yates, L. (2006). Is impact a measure of quality producing quality research and producing quality indicators of research in education. In J. Blackmore, J. Wright, \& V. Harwood (Eds.), Counterpoints on the quality and impact of educational research (pp. 119-132). Melbourne: Australian Association for Research in Education.

\section{Fazal Rizvi}

Department of Educational Policy Studies

University of Illinois at Urbana Champaign

USA 


\section{University Library}

\section{- M M N E R VA A gateway to Melbourne's research publications}

Minerva Access is the Institutional Repository of The University of Melbourne

Author/s:

Rizvi, FA

Title:

Internationalization and the assessment of research quality in education

Date:

2009

Citation:

Rizvi, F. A. (2009). Internationalization and the assessment of research quality in education. Besley, $\mathrm{T}(\mathrm{Ed}$.). Assessing the quality of educational research in higher education: international perspectives, (1), pp.49-58. Sense Publishers.

Persistent Link:

http://hdl.handle.net/11343/31463 